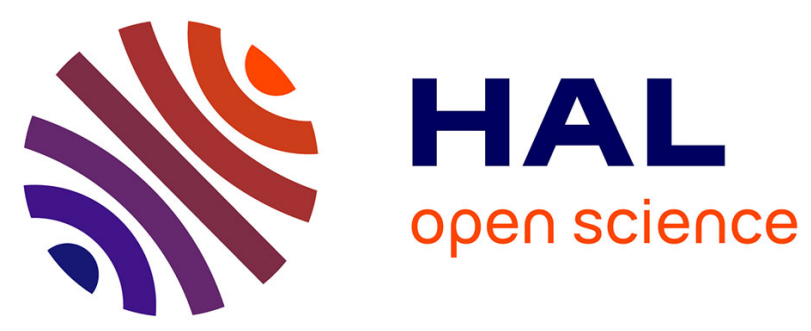

\title{
Stochasticity of Pores Interconnectivity in Li-O2 Batteries and its Impact on the Variations in Electrochemical Performance
}

\author{
Amangeldi Torayev, Alexis Rucci, Pieter C M M Magusin, Arnaud \\ Demortière, Vincent de Andrade, Clare Grey, Céline Merlet, Alejandro Franco
}

\section{To cite this version:}

Amangeldi Torayev, Alexis Rucci, Pieter C M M Magusin, Arnaud Demortière, Vincent de Andrade, et al.. Stochasticity of Pores Interconnectivity in Li-O2 Batteries and its Impact on the Variations in Electrochemical Performance. Journal of Physical Chemistry Letters, 2018, 9 (4), pp.791-797. 10.1021/acs.jpclett.7b03315 . hal-01986199

\section{HAL Id: hal-01986199 \\ https://hal.science/hal-01986199}

Submitted on 18 Jan 2019

HAL is a multi-disciplinary open access archive for the deposit and dissemination of scientific research documents, whether they are published or not. The documents may come from teaching and research institutions in France or abroad, or from public or private research centers.
L'archive ouverte pluridisciplinaire HAL, est destinée au dépôt et à la diffusion de documents scientifiques de niveau recherche, publiés ou non, émanant des établissements d'enseignement et de recherche français ou étrangers, des laboratoires publics ou privés. 


\section{Stochasticity of pores interconnectivity in $\mathrm{Li}-\mathrm{O}_{2}$}

\section{batteries and its impact on the variations in}

\section{electrochemical performance}

Amangeldi Torayev ${ }^{1,2,3}$, Alexis Rucci ${ }^{1,4}$, Pieter C. M. M. Magusin ${ }^{2,3}$, Arnaud Demortière ${ }^{1,2,4}$,

Vincent De Andrade ${ }^{5}$, Clare P. Grey ${ }^{2,3}$, Céline Merlet ${ }^{3,4,6}$, Alejandro A. Franco 1,2,4,7,*

${ }^{1}$ Laboratoire de Réactivité et Chimie des Solides (LRCS), CNRS UMR 7314, Université de

Picardie Jules Verne, HUB de l'Energie, Rue Baudelocque, 80039 Amiens, France

${ }^{2}$ ALISTORE-European Research Institute, Fédération de Recherche CNRS 3104, HUB de l'Energie, Rue Baudelocque, 80039 Amiens, France

${ }^{3}$ Department of Chemistry, University of Cambridge, Lensfield Road, Cambridge CB2 1EW, United Kingdom

${ }^{4}$ Réseau sur le Stockage Electrochimique de l'Energie (RS2E), Fédération de Recherche CNRS 3459, HUB de l'Energie, Rue Baudelocque, 80039 Amiens, France

${ }^{5}$ X-Ray Science Division, Advanced Photon Source, Argonne National Laboratory, Lemont, USA 
${ }^{6}$ CIRIMAT, Université de Toulouse, CNRS, INPT, UPS, Université Toulouse 3 Paul Sabatier, Bât. CIRIMAT, 118, route de Narbonne 31062 Toulouse cedex 9, France.

${ }^{7}$ Institut Universitaire de France, 103 Boulevard Saint-Michel, 75005 Paris, France

AUTHOR INFORMATION

Corresponding Author

*alejandro.franco@,u-picardie.fr

ABSTRACT. While large dispersions in electrochemical performance have been reported for lithium oxygen batteries in the literature, they have not been investigated in any depth. The variability in the results is often assumed to arise from differences in cell design, electrode structure, handling and cell preparation at different times. An accurate theoretical framework turns out to be needed to get a better insight into the mechanisms underneath and to interpreting experimental results. Here, we develop and use a pore network model to simulate the electrochemical performance of three-dimensionally resolved lithium-oxygen cathode mesostructures obtained from TXM nano-computed tomography. We apply this model to the 3D reconstructed object of a Super P carbon electrode and calculate discharge curves, using identical conditions, for four different zones in the electrode and their reversed configurations. The resulting galvanostatic discharge curves show some dispersion, (both in terms of capacity and overpotential) which we attribute to the way pores are connected with each other. Based on these results, we propose that the stochastic nature of pores interconnectivity and the microscopic 
arrangement of pores can lead, at least partially, to the variations in electrochemical results observed experimentally.

\section{TOC GRAPHICS}

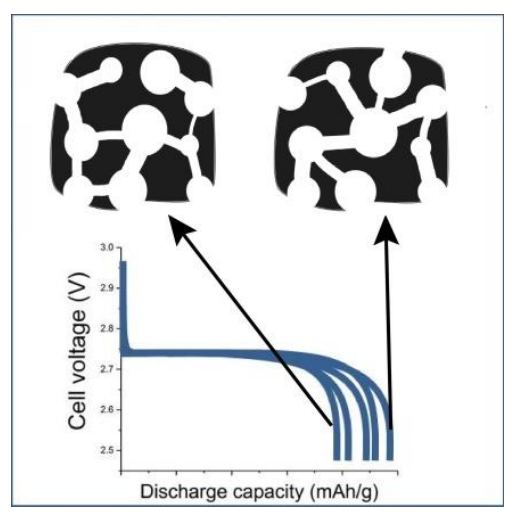

KEYWORDS. $\mathrm{Li}_{-} \mathrm{O}_{2}$ Battery, Pore interconnectivity, Stochasticity, Pore Network Model, Tomography, Reproducibility.

Since Abraham and Jiang demonstrated the first proof of concept of an aprotic $\mathrm{Li}^{-\mathrm{O}_{2}}$ battery, there has been a significant interest due to its superior theoretical capacity $\left(5.2 \mathrm{kWh} \cdot \mathrm{kg}^{-1}\right)$ compared to state of the art Li-ion batteries. ${ }^{1,2}$ In the last two decades numerous aspects of $\mathrm{Li}-\mathrm{O}_{2}$ batteries have been investigated. Research efforts have demonstrated how the positive electrode mesostructure affects the cell capacity, ${ }^{3-6}$ the influence of the electrolyte stability and its contribution to the cell performance, ${ }^{7,8}$ and the use of mediators to favor formation of large discharge particles. ${ }^{9-11}$ There has been a wide range of capacities reported in the literature, going from a few hundreds of $\mathrm{mAh} \cdot \mathrm{g}^{-1} 4,12$ to $29,375 \mathrm{mAh} \cdot \mathrm{g}^{-1}$ for catalyzed porous graphene 
nanostructures $^{13}$, and 37,523 mAh.g ${ }^{-1}$ for carbon electrodes with tailored architectures. ${ }^{14}$ These works use different types of carbons and operating conditions. However, even if only a single parameter is altered, the results can differ significantly. Meini et al. reported that the discharge capacities of Ketjenblack EC600JD and Black Pearls 200 increase from around $438 \mathrm{mAh} . \mathrm{g}^{-1}$ and $517 \mathrm{mAh} . \mathrm{g}^{-1}$ to $1833 \mathrm{mAh} \cdot \mathrm{g}^{-1}$ and $2168 \mathrm{mAh} \cdot \mathrm{g}^{-1}$, respectively, when simply replacing the diethylene glycol dimethyl ether solvent by the tetraethylene glycol dimethyl ether solvent. ${ }^{4}$ As shown by Read, simply using different pressing methods during electrode preparation can affect the discharge capacity significantly. ${ }^{15}$ In his work, a Super P based electrode with PTFE binder is prepared by hot and cold pressing methods and the discharge capacity obtained for the hot pressing approach is $1347 \mathrm{mAh} \cdot \mathrm{g}^{-1}$ while a capacity of $2120 \mathrm{mAh} \cdot \mathrm{g}^{-1}$ is achieved for the cold pressed one. All these studies have shown that $\mathrm{Li}^{-\mathrm{O}_{2}}$ batteries are extremely sensitive to operating conditions and cell components.

The sensitive nature of $\mathrm{Li}^{-} \mathrm{O}_{2}$ batteries leads to a non-negligible dispersion of experimental results. Griffith et al. reported reproducibility tests for 60 cells at 5 different current densities via well controlled experimental procedures, yet still a large variation of discharge capacities was observed. ${ }^{16}$ The dispersion of results is observed in experiments but insufficient attention is paid to the origin of this phenomenon. It is often assumed to result from the uncertainty in the material quantities (e.g., mass loading, electrolyte amount), handling issues or variations from one experiment to another.

On the modelling side, the common approach to study $\mathrm{Li}^{-\mathrm{O}_{2}}$ batteries is to use continuum models and to capture the effects of pore interconnectivity via a tortuosity factor. The tortuosity is usually described via the Bruggeman relationship that oversimplifies the role of pore sizes and connectivity on transport. ${ }^{17-19}$ Recently, Mehta et al. showed, for the first time, that the local 
variation of porosity and carbon surface area (CSA) in the cathode can lead to variations in performance as well. ${ }^{20}$ In their model, the positive electrode is discretized into fine meshes, and each mesh is assigned slightly different porosity and CSA values. The porosity and CSA values are chosen based on the overall properties and standard deviations at the macroscopic level. However, the model uses a mean field approach and does not explicitly consider interconnectivity of pores, or pore size distribution (PSD). As such the importance of transport and changes in the mesostructure during the cell operation can be overlooked.

To investigate the effect of pore interconnectivity on the electrochemical performances of carbon electrodes, we developed a pore network model (PNM), which enables us to calculate transport properties and simulate electrochemical reactions in three dimensional (3D) porous structures. A 3D structure of Super P type carbon is obtained from TXM (Transmission X-ray Microscopy) nano-computed tomography with phase contrast imaging using synchrotron X-ray source (APSANL). The 3D reconstructed structure allows us to generate porous structures with realistic porosities and pore interconnectivities. Using this model and porous structures, we show that, without altering the mesh porosity or the CSA, mesoscopic differences in the porous cathodes, namely the pores interconnectivity and the dynamics of pore clogging upon cell discharge, can also lead to a dispersion of the electrochemical performances. 


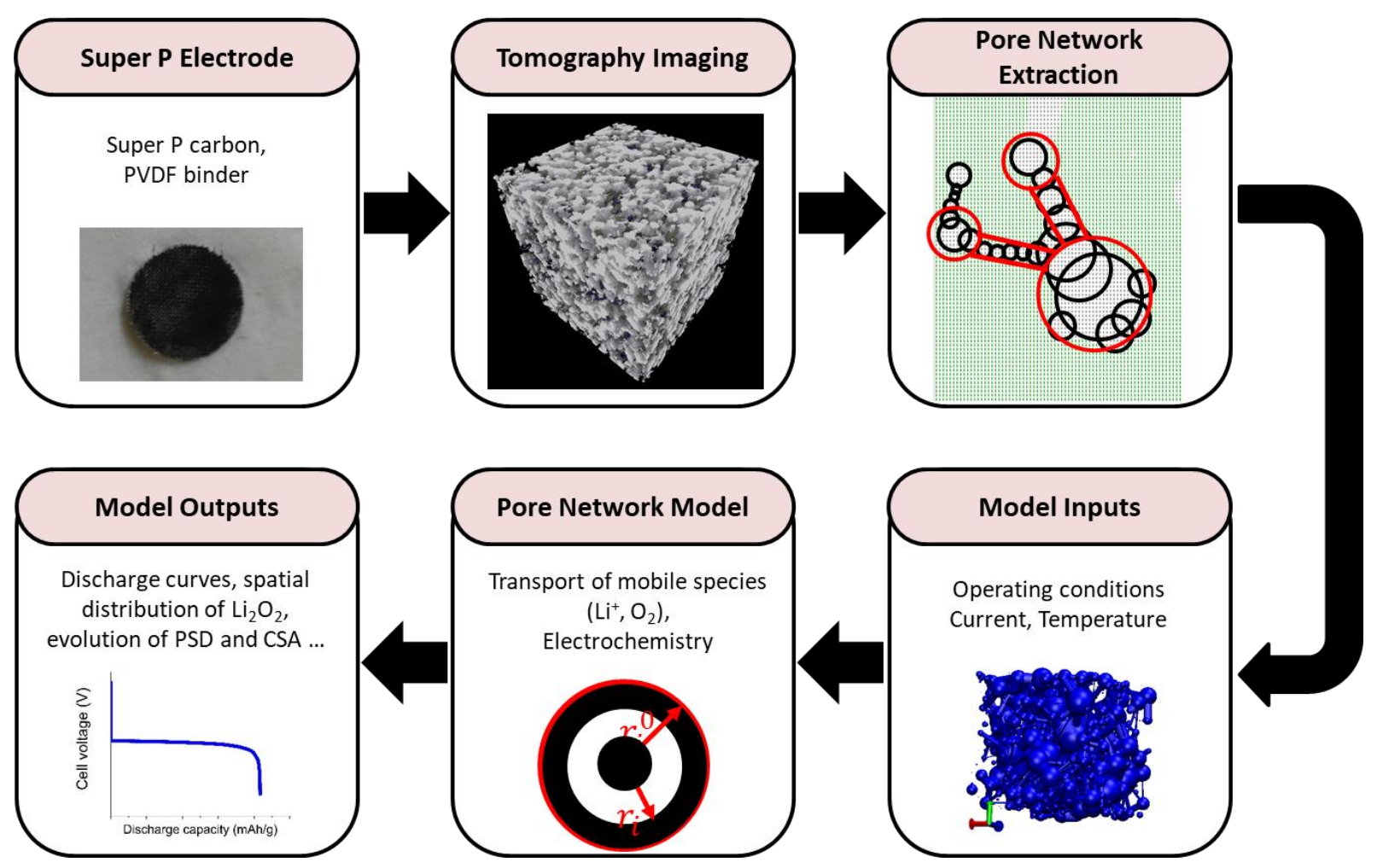

Figure 1. Workflow of our modeling approach.

The calculation of model discharge curves is made here following several steps as shown in Figure 1. The initial step is experimental and consists in preparing a porous carbon electrode made of Super P carbon. Prior to the thresholding treatment (using FIJI and AMIRA) to make the segmentation and convert the image stack into a binary file, the tomogram (3000 projections) was properly reconstructed using Tomopy Python script. ${ }^{21}$

Then, the void (pore) space in the tomography data is mapped to spherical and cylindrical pores using the maximal ball approach ${ }^{22}$ and a $3 \mathrm{D}$ pore network is extracted. We then simulate a $\mathrm{Li}-\mathrm{O}_{2}$ battery using the PNM approach on the extracted 3D pore network. 
For the pore network extraction, an open source code developed by Dong et al. is utilized and adapted to the current system. ${ }^{23}$ To extract the pore network, a pore is assigned to each void voxel of the tomography data and expanded till a carbon site is reached. After that an iterative process is carried out to identify the clusters of overlapping pores which are also called pore families, connected by bottlenecks (see supplementary information for details).

After identifying pore families (two are shown in Figure 2a), only two parameters need to be defined: an effective pore radius for each pore family and the length of the throats which connect these effective pores. To assign these parameters we use a different approach from the one reported by Dong et al. $^{23}$ They use a parameter called the pore-throat segmentation coefficient $(\alpha)$ to determine the effective pore radius and throat length. To calculate the radii of the effective pores, the distances between the center of the parent pores and the bottleneck pore $\left(l_{i}^{t}\right.$ and $\left.l_{j}^{t}\right)$ are calculated (Figure 2b) and the radii of the effective pores are given by:

$$
\begin{gathered}
l_{i}=l_{i}^{t}\left(1-\alpha \frac{r_{t}}{r_{i}}\right) \\
l_{j}=l_{j}^{t}\left(1-\alpha \frac{r_{t}}{r_{j}}\right) \\
l_{t}=l_{i j}-l_{i}-l_{j}
\end{gathered}
$$

where $l_{i}, l_{j}, l_{t}$ are radii of the effective pore for pore family $i, j$ and the length of the throat, (Figure $2 \mathrm{~d}$ ), $r_{t}$ is the radius of the throat; $r_{i}$ is the radius of the parent pore for pore family $i ; l_{i j}$ is the distance between centers of parent pores $i$ and $j$. This method has two caveats; first, it uses a fitting parameter $\alpha$ and second, it can assign more than one effective radius for a pore family depending on the number of throats it has. We amended this method to assign the effective pore 
radius $\left(l_{i}\right)$ so that the volume of the effective pore is equal to the total volume of the pore family (Figure 2c). A 3D pore network is then obtained (Figure 2e).

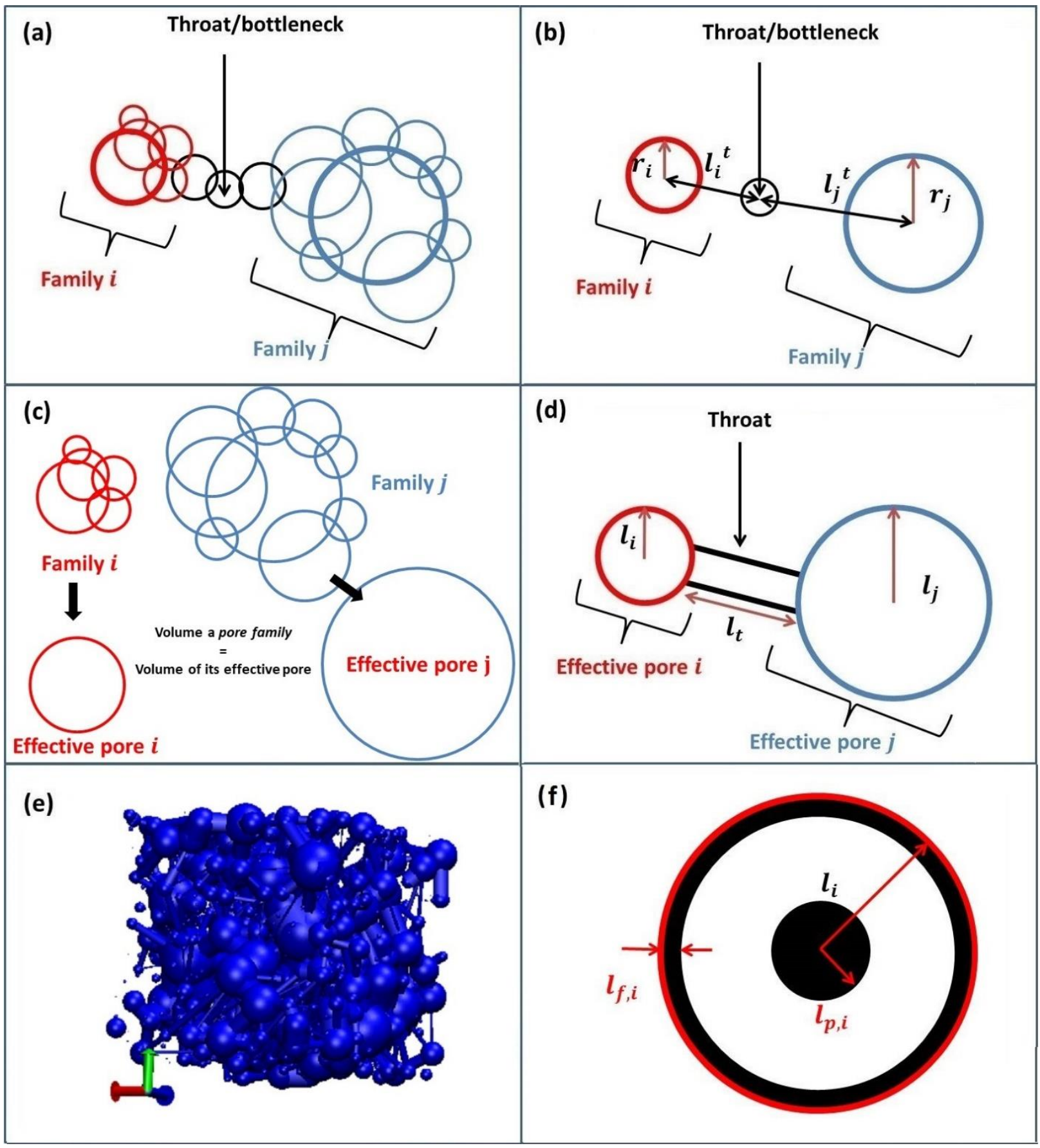

Figure 2. (a)-(d) Schematic illustrations of the pore network extraction. (a) Two pore families connected via a bottleneck. (b) Dong et al. approach to define effective pore radii and throat 
lengths. ${ }^{23}$ (c) Approach used in this work to assign effective pore radii (d) Effective pores and throat obtained after assigning effective pore radiuses and throat lengths either by approaches (b) or (c). (e) Final pore network obtained using the pore network extraction. (f) Illustration of the two mechanisms considered for $\mathrm{Li}_{2} \mathrm{O}_{2}$ (in black) growth in our model: particle and thin film formation.

The resolution of X-ray tomography (20 nm voxel size in this work) cannot capture nanopores, and the capacity contribution from those pores is neglected here. We note that experiments on activated carbons, for which the high surface area largely originates from nanopores, do not report high capacities. ${ }^{5,24}$ This is presumably because these pores are readily blocked. However, this issue with acquiring the $3 \mathrm{D}$ structure through experiments can be bypassed via in-silico structure generation, and does not restrict the capability of our model.

The transport equations for the PNM are adapted from the polymer electrolyte membrane fuel cell work of Fazeli et al. ${ }^{25}$ The evolution of the concentration in each pore is calculated by solving the balance equation 4 , written in terms of the fluxes between neighboring pores

$$
\frac{d c_{i, x}}{d t}=\sum_{j}^{\text {neighbours }} k_{i j, x}\left(c_{j, x}-c_{i, x}\right)+s_{i, x}
$$

where $c_{i, x}$ is the concentration of mobile species $x\left(\mathrm{Li}^{+}\right.$or $\left.\mathrm{O}_{2}\right)$ in the pore $i$ and $c_{j, x}$ is the concentration in the pores connected to $i . k_{i j, x}$ is the transfer parameter between pores $i$ and $j$, and $s_{i, x}$ is the sink term for species $x$ which is calculated by the electrochemical reactions taking place in pore $i . k_{i j, x}$ is a function of the bulk diffusion coefficient of $x\left(D_{0, x}\right)$, the distance 
between the centers of pores $i$ and $j$, and the cross-sectional areas of pores $i, j$ and the connecting throat, which are $A_{i}, A_{j}$ and $A_{t}$ respectively, and can be formulated as

$$
\begin{gathered}
k_{i j, x}=\left(\frac{1}{k_{i, x}}+\frac{1}{k_{j, x}}+\frac{1}{k_{t, x}}\right)^{-1} \\
k_{i, x}=\frac{A_{i} D_{0, x}}{l_{i}} \\
k_{j, x}=\frac{A_{j} D_{0, x}}{l_{j}} \\
k_{t, x}=\frac{A_{t} D_{0, x}}{l_{t}}
\end{gathered}
$$

The cross-sectional areas are calculated by:

$$
\begin{aligned}
& A_{i}=\pi\left[\left(l_{i}-t_{f, i}\right)^{2}-t_{p, i}{ }^{2}\right] \\
& A_{j}=\pi\left[\left(l_{j}-t_{f, j}\right)^{2}-t_{p, j}{ }^{2}\right] \\
& A_{t}=\pi\left[\left(r_{t}-t_{f, t}\right)^{2}-t_{p, t}{ }^{2}\right]
\end{aligned}
$$

$t_{f, i}$ and $t_{p, i}$ are the thickness of the $\mathrm{Li}_{2} \mathrm{O}_{2}$ thin film and the radius of the $\mathrm{Li}_{2} \mathrm{O}_{2}$ particle formed in the pores considered (Figure 2f). The transport coefficients calculated here neglect the electromigration. This assumption seems reasonable as the discharge capacity is mainly limited by the $\mathrm{O}_{2}$ (neutral) transport.

The electrochemical discharge reaction generally does not happen in a single step but can involve several intermediate steps such as the formation of superoxides $\left(\mathrm{LiO}_{2}\right)^{26,27}$ In this work, for simplicity reasons, an overall reaction is considered

$$
2 \mathrm{Li}^{+}+\mathrm{O}_{2}+2 e^{-} \rightarrow \mathrm{Li}_{2} \mathrm{O}_{2}
$$

The associated electrochemical reaction rate is formulated as 


$$
v=k_{f} a_{f} \exp \left(\frac{-\beta n F\left(U-U_{0}\right)}{R T}\right)-k_{b} a_{b} \exp \left(\frac{(1-\beta) n F\left(U-U_{0}\right)}{R T}\right)
$$

where $k_{f}, k_{b}$ are the forward and backward reaction rate constants; $a_{f}$ and $a_{b}$ are the activities of $\mathrm{Li}^{+}, \mathrm{O}_{2}$ and $\mathrm{Li}_{2} \mathrm{O}_{2}$ respectively; $\beta$ is the charge transfer coefficient, $n$ is the number of electrons involved in the electrochemical reaction, $U$ is the electrostatic potential of the electrode and $U_{0}$ is the standard potential of the reaction; $R$ is the universal gas constant, $T$ is the temperature and $F$ is Faraday's constant. The cell potential $U$ is calculated by equating the sum of all currents from all the pores in the network to the input current density or discharge current $\left(I_{t o t}\right)$

$$
I_{\text {tot }}=\sum_{i=1}^{\text {Allpores }} S A_{i} F v
$$

where $S A_{i}$ is the surface area of pore $i$, which can be either a spherical or a cylindrical pore with the surface area being considered accordingly.

The discharge products can follow two types of pathways: the formation of large particles and the deposition of a thin film. Experimentally, the $\mathrm{Li}_{2} \mathrm{O}_{2}$ formation path depends on several parameters, such as the electrolyte used,$^{28}$ the current density ${ }^{29}$ and the presence of impurities (e.g. the $\mathrm{H}_{2} \mathrm{O}$ content in the electrolyte enhancing the $\mathrm{LiO}_{2}$ solubility). ${ }^{30}$ In our model, both the formation of large particles and the deposition of a thin film are considered using the escape function concept reported in our previous work. ${ }^{31}$ The escape function is the probability of $\mathrm{LiO}_{2}$ to escape or dissolve in the electrolyte once it is formed close to the carbon surface. The dissolved $\mathrm{LiO}_{2}$ is assumed to follow a solution phase mechanism leading to the formation of large $\mathrm{Li}_{2} \mathrm{O}_{2}$ particles, whereas the $\mathrm{LiO}_{2}$ molecules adsorbed on the carbon surface lead to thin film formation. The discharge reaction, including the escape function $(\chi)$, can be represented by equations 11.a to 11.d, and the amounts of $\mathrm{Li}_{2} \mathrm{O}_{2}$ particles and thin films (equation 11.e) can be 
calculated by combining these equations. The escape function values used in this work are given in the supplementary information.

$$
\begin{gathered}
\mathrm{Li}^{+}+\mathrm{O}_{2}+e^{-} \rightarrow \mathrm{LiO}_{2} \\
\mathrm{LiO}_{2} \rightarrow \chi \mathrm{LiO}_{2, \text { dis }}+(1-\chi) \mathrm{LiO}_{2, \text { ads }} \\
\chi \mathrm{LiO}_{2, \text { dis }} \rightarrow \frac{\chi}{2} \mathrm{Li}_{2} \mathrm{O}_{2, \text { particle }}+\frac{\chi}{2} \mathrm{O}_{2} \\
(1-\chi) \mathrm{LiO}_{2, a d s}+(1-\chi) \mathrm{Li}^{+}+(1-\chi) e^{-} \rightarrow(1-\chi) \mathrm{Li}_{2} \mathrm{O}_{2, \text { film }} \\
2 \mathrm{Li}^{+}+\mathrm{O}_{2}+2 e^{-} \rightarrow \frac{2-2 \chi}{2-\chi} \mathrm{Li}_{2} \mathrm{O}_{2, \text { film }}+\frac{\chi}{2-\chi} \mathrm{Li}_{2} \mathrm{O}_{2, \text { particle }}
\end{gathered}
$$

To investigate the effect of mesostructural differences on the dispersion in electrochemical results and analyze it further, we select four random zones from a single tomography image acquired for a Super P carbon electrode (Figure 3a) and apply our model to these distinct regions. The active surface areas and porosity values are very close to each other (Table 1). There is only a difference of about $7 \%$ for the porosity and $8 \%$ for the CSA. The PSDs are also superimposed (Figure 3b).

While the four selected regions have similar CSAs, porosities and PSDs, the discharge curves of these four slices show a significant dispersion of capacities for the three current densities explored (Figure 3c). The relative differences between the discharge capacities are $29 \%$ for 400 $\mathrm{mA} \cdot \mathrm{g}^{-1}, 23 \%$ for $100 \mathrm{~mA} \cdot \mathrm{g}^{-1}$ and $16 \%$ for $20 \mathrm{~mA} \cdot \mathrm{g}^{-1}$. These variations in capacities are much larger than the ones for porosity and CSA. To make sure these differences are not due to slight differences in porosities and CSAs, the four electrodes are flipped; the air inlet and separator sides of the cathode are exchanged. In this case the macroscopic properties are identical. Yet, the 
discharge profiles again show variations (Figure 3d). The main reasons of these large dispersions are inherent to the stochastic nature of the pores interconnectivity and the dynamic change of the porous mesostructure.

Table 1. Porosities and specific surface areas for the four zones.

\begin{tabular}{l|ll}
\hline Zone number & Porosity & Surface area \\
\hline 1 & 0.356 & $7.97 \times 10^{6} \mathrm{~m}^{2} / \mathrm{m}^{3}$ \\
2 & 0.352 & $7.68 \times 10^{6} \mathrm{~m}^{2} / \mathrm{m}^{3}$ \\
3 & 0.382 & $7.67 \times 10^{6} \mathrm{~m}^{2} / \mathrm{m}^{3}$ \\
4 & 0.363 & $7.27 \times 10^{6} \mathrm{~m}^{2} / \mathrm{m}^{3}$ \\
\hline
\end{tabular}


(a)

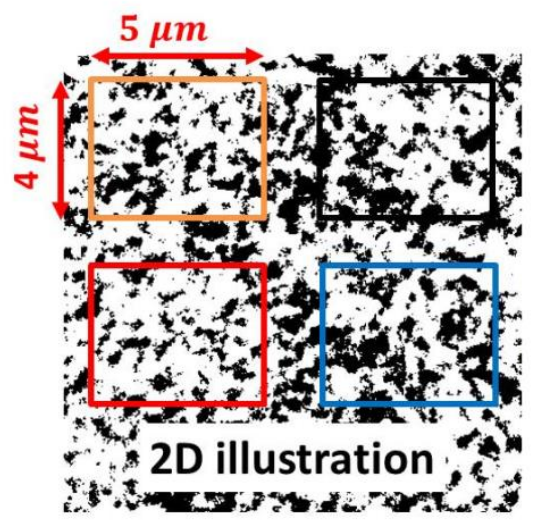

(c)

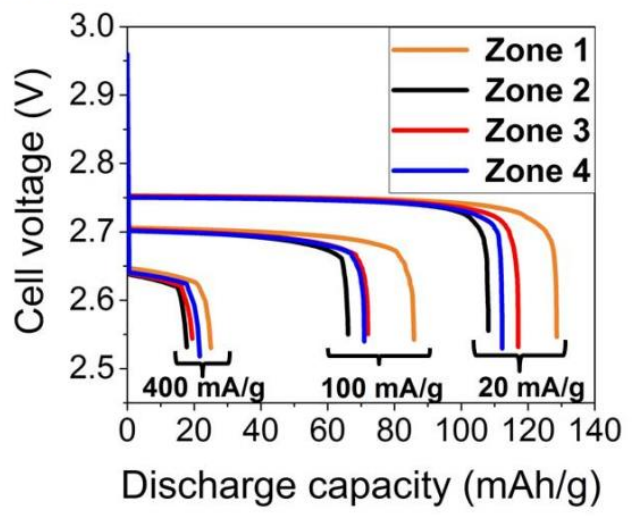

(b)

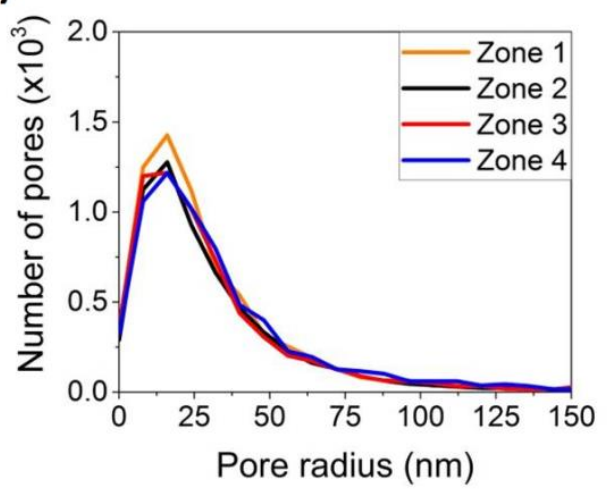

(d)

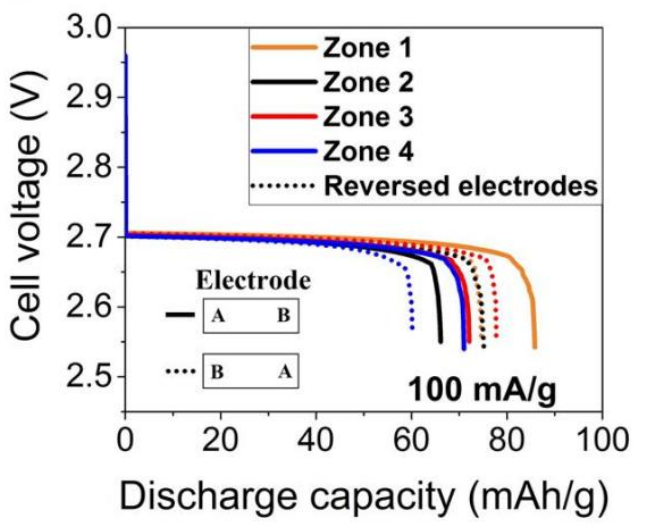

Figure 3. (a) Illustration of the 4 zones taken from the tomography data. (b) PSDs corresponding to the four slices. (c) Calculated discharge curves for the four slices at three different applied current densities. (d) Calculated discharge curves for the flipped electrodes (A: separator side, B: air inlet side).

For the four selected zones, while the macroscopic properties are similar, the mesoscopic arrangement of pores is not identical and in particular the pores are not connected in the same fashion. In $\mathrm{Li}-\mathrm{O}_{2}$ batteries, the transport of $\mathrm{O}_{2}$ and $\mathrm{Li}^{+}$in the electrolyte crucially determines the cell capacity, and it is expected that the differences in interconnectivity and pore arrangements will generate a significant dispersion. Besides, unlike in Li-ion batteries, discharge products of $\mathrm{Li}-\mathrm{O}_{2}$ batteries are solid particles that fill up the porous volume. As such, the porous structure 
dramatically evolves along the discharge. This is illustrated in Figure 4 which shows the evolution of the pore size distribution along the discharge for zone 2 and the number of inactive pores as a function of time for the same zone in normal and reversed configurations. Once a pore gets clogged, it does not only affect itself but also its neighboring pores. This blocks the transport of $\mathrm{O}_{2}$ and $\mathrm{Li}^{+}$to the connected pores through this clogged pore. This can impede long range transport and also form isolated regions in the pore network which do not contribute to the cell capacity.

(a)

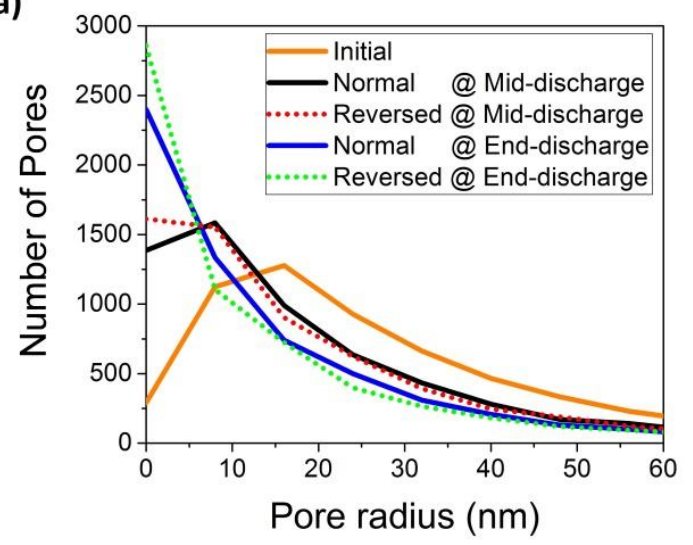

(b)

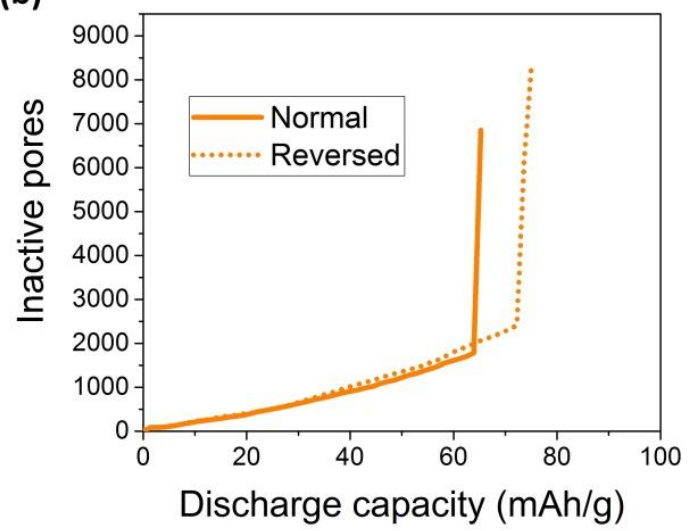

Figure 4. (a) Calculated evolution of PSDs and (b) calculated number of inactive pores along discharge for Zone 2 at $100 \mathrm{~mA} \cdot \mathrm{g}^{-1}$, in normal and reversed configurations. Pores are considered inactive if they are i) clogged, ii) passivated by the $\mathrm{Li}_{2} \mathrm{O}_{2}$ deposit or iii) depleted in $\mathrm{O}_{2}$ (see $\mathrm{SI}$ for a detailed description of the criteria).

Figure 5 shows snapshots of the oxygen concentration at two different depths of discharge for two structures. For the snapshots corresponding to point (a), there are no significant differences of oxygen concentrations in the electrode volume. Yet, for both zones, there are some pores and clusters of pores that are depleted from oxygen, (represented in blue in Figure 5). These pore clusters are isolated from the oxygen source due to pore/throat clogging. They do not contribute 
to the cell capacity once they become isolated. This long range effect explains why pore size distribution evolution is insufficient to explain the discharge capacities observed. Instead, we have to consider all the possible reasons of pore inactivity as given in Figure S3. This is a clear added-value of this model compared to continuum and mean-field computational approaches. This type of features cannot be captured without an explicit description of pores interconnectivity. ${ }^{17-19}$ For the color maps of the two zones at point (b), the concentration profiles are very different. This is because along the discharge the porous network evolves due to formation of $\mathrm{Li}_{2} \mathrm{O}_{2}$ discharge products and several pores get clogged. For zone 2, there is lack of $\mathrm{O}_{2}$ transport and a huge gradient of concentration is observed. At this point, the transport of $\mathrm{O}_{2}$ cannot catch up with the consumption rate and the cell voltage drops. 


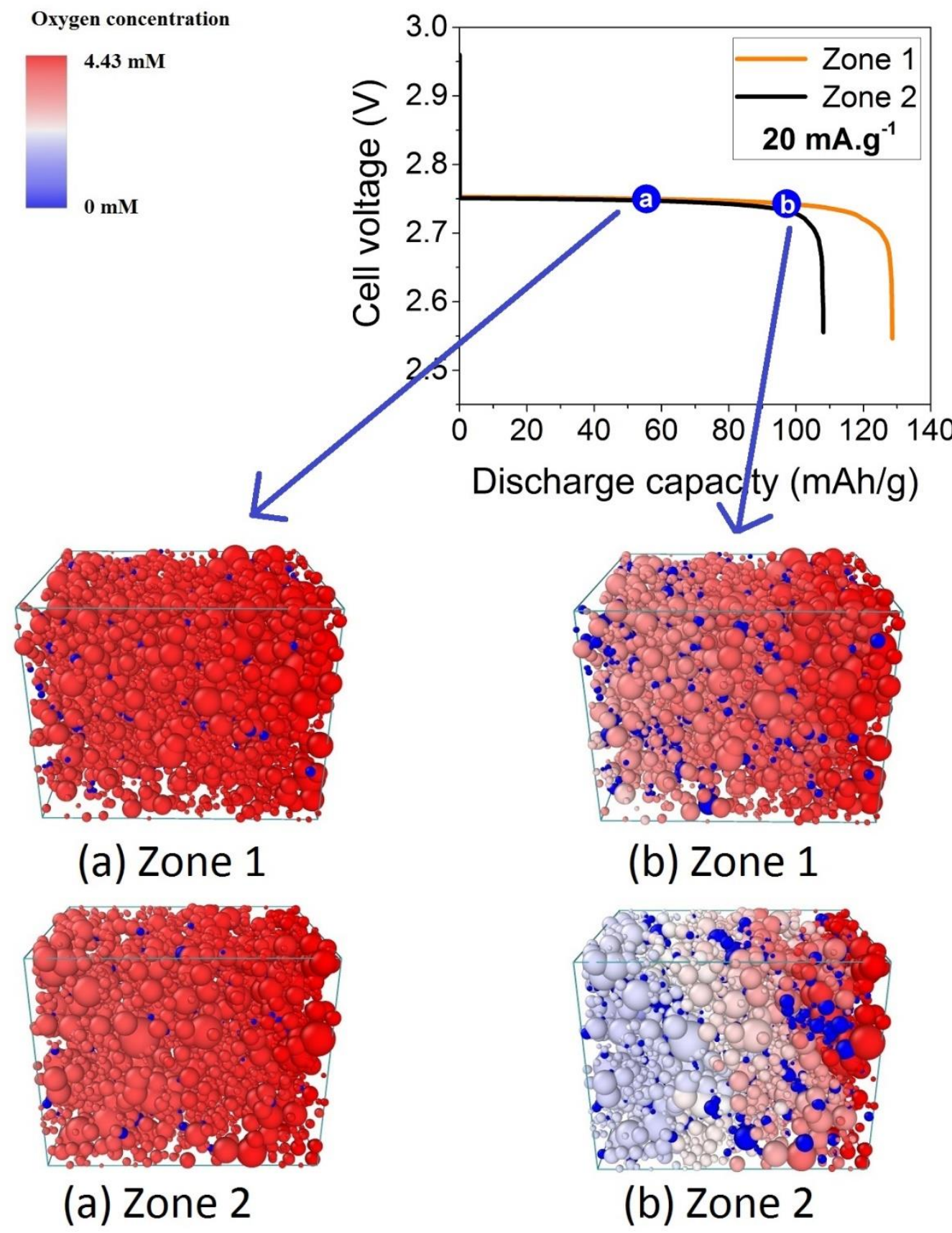

Figure 5. Calculated oxygen concentration color maps at two different depths of discharge, (a) $55 \mathrm{mAh} \cdot \mathrm{g}^{-1}$ and (b) $97 \mathrm{mAh} \cdot \mathrm{g}^{-1}$, for two zones at $20 \mathrm{~mA} \cdot \mathrm{g}^{-1}$ discharge current density. Throats (cylindrical pores) are removed for clarity. 
In conclusion, we have developed a new model to calculate discharge curves for $\mathrm{Li}^{-} \mathrm{O}_{2}$ batteries directly comparable with experiments. The model uses tomography images as an input which allows us to generate a realistic $3 \mathrm{D}$ porous structure for which we can simulate the electrochemical performances. To the best of our knowledge, neither the pore network extraction approach nor the PNM have been used so far in the context of $\mathrm{Li}_{-} \mathrm{O}_{2}$ batteries and batteries in general. Part of the work reported here was focused on adapting these two approaches, already used in other fields, to the case of batteries. With this model, we clearly demonstrate that extra insights can be gained by introducing a 3D representation of porous structures and an explicit description of the pores interconnectivity in modeling works. In particular, we show that the inherent stochastic nature of pore interconnectivity and the mesostructural differences contribute to the dispersion of results observed in experiments. Based on these results, we believe that the variations in the measured capacities/voltages should be reported when presenting experimental discharge curves. This is critically needed to allow comparison of data. Our newly developed model is a useful tool to compare performances of different electrode structures and suggests that structures with less bottlenecks and high porosity will give better electrochemical performance.

\section{ASSOCIATED CONTENT}

Supporting Information. A table of symbols and their descriptions, a table of parameters and their values, a description of the home-made python script used to convert gray scale tomography images to binary format files, details about the electrode preparation, the tomographic imaging, the procedure followed for electrochemical tests and additional details about the PNM model are provided along with detailed description and plot of inactive pores and 
gradient of discharge products along electrode thickness. Supporting information also includes two avi videos showing the calculated oxygen concentration color map along the discharge for normal and reversed electrodes (details provided in the Supporting Information text) and values of the escape function.

\section{AUTHOR INFORMATION}

The authors declare no competing financial interests.

\section{ACKNOWLEDGMENT}

Authors thank Yinghui Yin, PhD student at LRCS Amiens, for preparing the electrode for the tomography imaging. Authors also thank Abbos Shodiev, who was a summer intern student at LRCS Amiens, for discussions on adapting PNM to $\mathrm{Li}^{-\mathrm{O}_{2}}$ batteries. Authors thank the ALISTORE ERI for A.T.'s PhD funding. A.A.F. acknowledges the Institut Universitaire de France for funding support. C.M. acknowledges the School of the Physical Sciences of the University of Cambridge for funding through an Oppenheimer Research Fellowship. The authors acknowledge the European Union's Horizon 2020 research and innovation programmes for the

partial funding support through the POROUS4APP project (grant agreement 686163) and through the European Research Council (ERC) (grant agreement No 714581). This research used resources of the Advanced Photon Source, a U.S. Department of Energy (DOE) Office of Science User Facility operated for the DOE Office of Science by Argonne National Laboratory under Contract No. DE-AC02-06CH11357.

\section{REFERENCES}

(1) Christensen, J.; Albertus, P.; Sanchez-Carrera, R. S.; Lohmann, T.; Kozinsky, B.; Liedtke, 
R.; Ahmed, J.; Kojic, A. A Critical Review of Li/Air Batteries. J. Electrochem. Soc. 2012, 159 (2), R1.

(2) Abraham, K. M. A Polymer Electrolyte-Based Rechargeable Lithium/Oxygen Battery. $J$. Electrochem. Soc. 1996, 143 (1), 1.

(3) Franco, A. A.; Xue, K. H. Carbon-Based Electrodes for Lithium Air Batteries: Scientific and Technological Challenges from a Modeling Perspective. ECS J. Solid State Sci. Technol. 2013, 2 (10), M3084-M3100.

(4) Meini, S.; Piana, M.; Beyer, H.; Schwammlein, J.; Gasteiger, H. A. Effect of Carbon Surface Area on First Discharge Capacity of Li-O2 Cathodes and Cycle-Life Behavior in Ether-Based Electrolytes. J. Electrochem. Soc. 2012, 159 (12), A2135-A2142.

(5) Ding, N.; Chien, S. W.; Hor, T. S. A.; Lum, R.; Zong, Y.; Liu, Z. L. Influence of Carbon Pore Size on the Discharge Capacity of Li-O2 Batteries. J. Mater. Chem. A 2014, 2 (31), $12433-12441$.

(6) Xue, K.-H.; Nguyen, T.-K.; Franco, A. A. Impact of the Cathode Microstructure on the Discharge Performance of Lithium Air Batteries: A Multiscale Model. J. Electrochem. Soc. 2014, 161 (8), E3028-E3035.

(7) Kuboki, T.; Okuyama, T.; Ohsaki, T.; Takami, N. Lithium-Air Batteries Using Hydrophobic Room Temperature Ionic Liquid Electrolyte. J. Power Sources 2005, 146 (1-2), 766-769.

(8) Balaish, M.; Kraytsberg, A.; Ein-Eli, Y. A Critical Review on Lithium-Air Battery Electrolytes. Phys. Chem. Chem. Phys. 2014, 16 (7), 2801-2822.

(9) Bergner, B. J.; Schürmann, A.; Peppler, K.; Garsuch, A.; Janek, J. TEMPO: A Mobile Catalyst for Rechargeable Li-O2 Batteries. J. Am. Chem. Soc. 2014, 136 (42), 15054 
15064.

(10) Nasybulin, E.; Xu, W.; Engelhard, M. H.; Li, X. S.; Gu, M.; Hu, D.; Zhang, J. G. Electrocatalytic Properties of Poly(3,4-Ethylenedioxythiophene) (PEDOT) in Li-O2 Battery. Electrochem. commun. 2013, 29, 63-66.

(11) Chen, Y.; Freunberger, S. A.; Peng, Z.; Fontaine, O.; Bruce, P. G. Charging a Li-O2 Battery Using a Redox Mediator. Nat. Chem. 2013, 5 (6), 489-494.

(12) Wen, Z.; Shen, C.; Lu, Y. Air Electrode for the Lithium-Air Batteries: Materials and Structure Designs. Chempluschem 2015, 80 (2), 270-287.

(13) Sun, B.; Huang, X.; Chen, S.; Munroe, P.; Wang, G. Porous Graphene Nanoarchitectures: An Efficient Catalyst for Low Charge-Overpotential, Long Life, and High Capacity Lithium-Oxygen Batteries. Nano Lett. 2014, 14 (6), 3145-3152.

(14) Yang, W.; Qian, Z.; Du, C.; Hua, C.; Zuo, P.; Cheng, X.; Ma, Y.; Yin, G. Hierarchical Ordered Macroporous/Ultrathin Mesoporous Carbon Architecture: A Promising Cathode Scaffold with Excellent Rate Performance for Rechargeable Li-O2 Batteries. Carbon N. Y. 2017, 118, 139-147.

(15) Read, J. Characterization of the Lithium/Oxygen Organic Electrolyte Battery. J. Electrochem. Soc. 2002, 149 (9), A1190-A1195.

(16) Griffith, L. D.; Sleightholme, A. E. S.; Mansfield, J. F.; Siegel, D. J.; Monroe, C. W. Correlating Li/O2 Cell Capacity and Product Morphology with Discharge Current. ACS Appl. Mater. Interfaces 2015, 7 (14), 7670-7678.

(17) Ren, Y. X.; Zhao, T. S.; Tan, P.; Wei, Z. H.; Zhou, X. L. Modeling of an Aprotic Li-O2 Battery Incorporating Multiple-Step Reactions. Appl. Energy 2017, 187, 706-716.

(18) Sahapatsombut, U.; Cheng, H.; Scott, K. Modelling the Micro-macro Homogeneous 
Cycling Behaviour of a Lithium-air Battery. J. Power Sources 2013, 227, 243-253.

(19) Yin, Y.; Gaya, C.; Torayev, A.; Thangavel, V.; Franco, A. A. Impact of Li2O2 Particle Size on Li-O2 Battery Charge Process: Insights from a Multiscale Modeling Perspective. J. Phys. Chem. Lett. 2016, 7 (19), 3897-3902.

(20) Mehta, M.; Zhu, C.; Andrei, P. Statistical Analysis of Li-Oxygen Batteries. ECS Trans. 2017, 75 (22), 35-45.

(21) Silin, D.; Patzek, T. Pore Space Morphology Analysis Using Maximal Inscribed Spheres. Phys. A Stat. Mech. its Appl. 2006, 371 (2), 336-360.

(22) Silin, D. B.; Jin, G. D.; Patzek, T. W. Robust Determination of the Pore-Space Morphology in Sedimentary Rocks. J. Pet. Geol. 2004, 56 (5), 69-70.

(23) Dong, H.; Blunt, M. J. Pore-Network Extraction from Micro-Computerized-Tomography Images. Phys. Rev. E - Stat. Nonlinear, Soft Matter Phys. 2009, 80 (3), 1-11.

(24) Yang, X. hui; He, P.; Xia, Y. yao. Preparation of Mesocellular Carbon Foam and Its Application for Lithium/Oxygen Battery. Electrochem. commun. 2009, 11 (6), 11271130.

(25) Fazeli, M.; Hinebaugh, J.; Bazylak, A. Incorporating Embedded Microporous Layers into Topologically Equivalent Pore Network Models for Oxygen Diffusivity Calculations in Polymer Electrolyte Membrane Fuel Cell Gas Diffusion Layers. Electrochim. Acta 2016, 216, 364-375.

(26) Yin, Y.; Torayev, A.; Gaya, C.; Mammeri, Y.; Franco, A. A. Linking the Performances of Li-O2Batteries to Discharge Rate and Electrode and Electrolyte Properties through the Nucleation Mechanism of Li2O2. J. Phys. Chem. C 2017, 121 (36), 19577-19585.

(27) Belova, A. I.; Kwabi, D. G.; Yashina, L. V.; Shao-Horn, Y.; Itkis, D. M. Mechanism of 
Oxygen Reduction in Aprotic Li-Air Batteries: The Role of Carbon Electrode Surface Structure. J. Phys. Chem. C 2017, 121 (3), 1569-1577.

(28) Johnson, L.; Li, C.; Liu, Z.; Chen, Y.; Freunberger, S. A.; Ashok, P. C.; Praveen, B. B.; Dholakia, K.; Tarascon, J.-M.; Bruce, P. G. The Role of LiO2 Solubility in O2 Reduction in Aprotic Solvents and Its Consequences for Li-O2 Batteries. Nat. Chem. 2014, 6 (12), 1091-1099.

(29) Adams, B. D.; Radtke, C.; Black, R.; Trudeau, M. L.; Zaghib, K.; Nazar, L. F. Current Density Dependence of Peroxide Formation in the Li-O2 Battery and Its Effect on Charge. Energy Environ. Sci. 2013, 6 (6), 1772-1778.

(30) Aetukuri, N. B.; McCloskey, B. D.; Garciá, J. M.; Krupp, L. E.; Viswanathan, V.; Luntz, A. C. Solvating Additives Drive Solution-Mediated Electrochemistry and Enhance Toroid Growth in Non-Aqueous Li-O2batteries. Nat. Chem. 2015, 7 (1), 50-56.

(31) Xue, K.-H.; McTurk, E.; Johnson, L.; Bruce, P. G.; Franco, A. A. A Comprehensive Model for Non-Aqueous Lithium Air Batteries Involving Different Reaction Mechanisms. J. Electrochem. Soc. 2015, 162 (4), A614-A621. 